\title{
Three Dimensional (3D) Body Scanner for Apparel Shoppers Would Make Commerce Easier
}

\author{
Marie-Eve FAUST ${ }^{\mathrm{a} *}$ and Serge CARRIER ${ }^{\mathrm{b}}$ \\ ${ }^{a}$ Fashion Merchandising, School of Business Administration, Philadelphia University, USA; \\ ${ }^{\text {b}}$ Département de management et de technologie, Université du Québec à Montréal, Canada
}

\begin{abstract}
If a 5',8”, $115 \mathrm{lbs}$ woman, a 5',6”, $135 \mathrm{lbs}$ woman and a 5',9”, $125 \mathrm{lbs}$ woman all claim to wear a size 8 ([TC]2, 2004) then what are the measurements of the garment they purchase?

In the ancient regime measurements, all things differed from one place to another. Besides the livre poids-de-marc, that was the most consistent in time, the toise (linear measurement) Toise de France, Toise de Chalet, Toise du Perou or de l'Academie varied over time. Moreover each King, Duke and Mont Seigneur, had their own measurements for an aune, a pied (foot) and a pouce (thumb). Everyone used what was most appropriate according to the circumstances and their need. This lasted until the end of the Eighteen Century when Louis XVI convened les Etats Generaux. One of the critical issues written by French citizens in the Cahier de doleances was uniformity of weight and measures.

"Qu'il n'y ait plus sur le territoire deux poids et deux mesures. » ... "Variété de mesures et leurs dénominations bizarre jettent nécessairement de la confusion dans nos idées, de l'embarras dans le commerce. " [...]... différence des choses sous l'uniformité des noms. ” "La différence des poids et des mesures est cause qu'on nous dupe » (Guedj, 2000).
\end{abstract}

People were convinced the suppression of diversity in measures would facilitate commerce between buyers and sellers. The Academie des sciences made 'table raze' and decided that measurement uniformity would be based on something that was not arbitrary, thus ephemera. From that day, measurements were based on something universal, invariable and eternal : the meridian, measured by triangulation which served as the basis for what is today known as the meter.

This unit of measurement was extraordinary for linear measurements. It helped commercialization by ensuring that each piece of land be, from thereon, calculated in the same units.

But how can this measure apply to a three dimensional human body? How do these measures translate to produce garment matching these measurements? More importantly how can these measurements be conveyed in size labels?

A number of our previous papers present an overview of research conducted on women's body measurements, using data extracted from the latest national survey in the U.S.A., performed using a 3D body scanner. We demonstrated that the body scanning technology was accurate (if imprecise for a few specific parts of the body) and that women may be classified according to their body shape and size measurements. We further showed that even when classified, it is almost impossible to arrive at a manageable number of sizes when taking into consideration the whole spectrum of measurements and shapes.

These observations led us to conclude that manufacturers and retailers should stop using standard "numbered size labels" or "small, medium, large", and worst, use vanity sizing. We further believe apparel manufacturers and retailers should work with technology such as 3D body scanners. They could then either (1) use 3D body data measurements along with other technologies, software, or solutions to cut and sew garments specifically matching individuals' data (mass customization) or (2) use an individual's measurements to identify the standard sized garment that would suit them best. 3D body scanners (at least the one from [TC]2) are accurate, and, nowadays, relatively accessible. Contrary to the existing labeling system which uses standardized sizes, the 3D body scanner enables the seller to direct consumers toward garments that should fit their silhouette and size. Used in combination with visualization and communication technologies it could even allow for the socialization component so important in the shopping experience. Mass customization would reduce returns and waste of time as well as increase consumer satisfaction. Some of our previous research has demonstrated that being scanned and experiencing virtual visualization are part of a shopping experience that consumers are ready to experiment.

Yet even if we now have the most reliable measuring tools, communicating sizing information still needs to be improved. Manufacturers, retailers, consumers and academics must sit together and agree on a new size label.

* Dr. Marie-Eve Faust ; faustm@philau.edu 


\section{Introduction}

This paper investigates if there is an added value, in 2010, of using technology such as 3D body scanner. More specifically it examines if it may enhance the shopping experience from a consumer perspective as well as reduce returns for retailers.

The literature presents some of the variables influencing consumers in their purchasing process either when purchasing garments in stores or through distance shopping.

It is followed by an extract of paper from the previous decade presenting the vision of the world of the apparel industry in the future, i.e. 2010 with the emerging technologies such as: $3 D$ body scanner, Computer Aided Design (CAD). This paper did not discuss the arrival of mobiles phones or portable cellular telephones as well as the Smart Dressing Mirror (SDM) coupled to the apparel retailing merchandising business practices, nevertheless it presents many of these aspects.

We then present our results about the pros and cons of linking and promoting these technologies in the apparel industry: advantages of visualization for apparel designers, rewards of virtual $3 D$ prototyping for merchandisers, and lastly the benefit for the consumer of being able to visualize the garments on either a virtual mannequin or on his/her own avatar (i.e. retailing fashion in virtual reality).

This paper appraises Generation Y's perceptions on this forthcoming specific advancement. Our results show that our subjects view 3D body scanning technology positively and that it could be an efficient tool, both from a consumer's and from a seller's point of view.

\section{From the Artisan and Haute-Couture to Ready-to-Wear and Mass Customization}

The process of obtaining a garment has evolved over time. Up to the early 1800 , garments were cut and made-to-measure. The fitting and final touches were conducted before and during the production of the garment, thereby ensuring a proper fit (Boucher, 1996). The same was also true of what is now generally known as haute couture (Beaudot, 1999). These approaches, although costly, offer interaction between people and guarantee, to a limit, a well fitting product (Benetti and Guillaume, 1992).

The ready-to-wear, with its standardized sizes appeared during the last century (Burns and Bryant, 2002). It corresponded to the industrial revolution, the arrival of machineries such as sewing machines as well as with a trend in women's fashion toward less body hugging garments. Finally, the arrival of mass customization which could be perceived as a mix of ready-to-wear and customized apparel became a new way of thinking in the apparel industry. Nowadays, for what is left of handmade and haute couture, ready-to-wear and mass-customization survive in harmony with ready-to-wear occupying the largest share of the market.

\section{Criteria considered by consumers while making ready-to-wear purchase decision}

According to Eckman, Damhorst and Kadolph (1990), who investigated the criteria women use when evaluating ready-to-wear during in-store purchase decision, found that most were related to aesthetics. Aesthetics such as color/pattern, styling and fabric were 'the' variables. As for the trial process, fit, styling and appearance on the body were the most important criteria when deciding on adoption or rejection of a garment. According to these authors, since the adoption or the rejection of a garment is done at the fitting room, sales personel require training to help consumers before and at the fitting room in a positive manner, reinforcing aesthetic criteria. For Kwon, Paek and Arzeni (1991), these criteria are so important that they impact on whether consumers will be disposed to distance shopping or on contrary, they will limit themselves to shop only in situ. Their results showed that the major reason why people hesitate to shop by catalog (distance shopping) is because they cannot be sure of the quality and cannot touch and examine the products. In addition to their inability to get a closer look at the garment, they cannot try the garment on before purchasing it. They also revealed that their results show that the most important reason for shopping from a catalog (distance shopping), for those who do it, is to save time and is more convenient.

Catalog shopping may be convenient but results from Shim and Bickle (1993), who investigated older females catalog shoppers, showed that $64 \%$ of their respondents indicated they returned at least one item they bought during the last twelve months. Not only did consumers state that sizing and fit were the most significant concern but it was the major reason for returning merchandise. When it comes to younger females it seems that peers are the important socialization agents (Simpson and Duglas, 
1998); this younger generation's purchase decision is directly influenced by their peers whether when shopping by catalog (distance shopping) or in situ. Kim and Lee (2000), who investigated professional segmentation and their catalog behavior, stated that retailers must remember that convenience is the word. Retailers must gear toward convenience of catalog shopping such as promoting fast delivery, 1-800 numbers, merchandise index, accepting all major credit cards, ... They reinforce the fact that retailers must provide attractive illustrations and emphasize their wide assortment of styles, sizes and colors...

Many other studies were published since then (Lee and Johnson, 2002; Park and Stoel, 2002; Siddiqui, O'Malley, McColl and Birtwistle, 2003; Azuna and Fernie, 2003; Goldsmith and Flynn, 2004, Spence, Robb, Timmins and Chantler, $2004, \ldots$ ) and authors continue to investigate these variables. Not only do re-emphasize that these variables play an important role in the shopping process but they argue that they are also playing a major role in the globalized world of the Internet. Socializing, for the younger generation, leads to the creation of virtual worldwide networks.

\section{Variables enhancing the shopping experience: Aesthetics, Fit and Socialization.}

Selection of garments, of all time, has been influenced by aesthetics, fit and socialization.

Aesthetics: Humans wear garments to protect themselves, to cover their nudity and to ornate themselves. (Leroi-Gourham, 1973; Sommier, 2000). They are fashionable in the sense that fashion is the prevalent conduct or dress to reflect the style or trends adopted at a given point in time. The choices relative to fashion can make a statement relating social, political or economic concerns, psychographic as well as demographic characteristics of the individual. Garments are therefore used to position oneself within a social group (Barthe, 1975; Beaudrillard, 1984; Yonnet, 1985).

Fit: Reasons for fit issues are multiple. All manufacturers do not use the national standards. Many prefer to use their own. According to Orzechowski and Forney (1998) manufacturers have many potential sources of body dimensions available: One could be the professional fit models. Another are the statistics provided by their government or standard industry dress forms. It could also come from databases compiled by private or non-profit organizations or from databases from other industry such as the automobile. It often reflects company's target consumers or their competitors' garments. Manufacturers often design their clothes for one specific shape or model size that may be different from the one used by other manufacturers because their target differs in age or origin (Beazley, 1997). Lastly even if most of them use the same three key point measurements, bust, waist and hips, reliability of manual measurements of the human body is arguable because two persons may not measure at the exact same point. All of the above makes it complex for retailers and creates a real chaotic situation for consumers

Socialization: For some people, the buying process is perceived as a pleasurable experience. For some others, it is a mere necessity (De Fondaumiere and Morath, 2000; Kind and Hathcote, 2000). Forsythe and Bailey (1996) along with Tauber (1972) go even further and state that shopping may be 'a social act' and an opportunity to interact. For some people, the shopping process itself provides the opportunity to interact since people can get advice and exchange ideas before buying the garments (Hart and Belinda, 2001; Simpson and Douglas, 1998). In the store context this advice is often provided by the sales person (Otieno, 2000). It may also come from friends or relatives accompanying the shopper as long as this one is allowed to get to the fitting room area. Not too long ago, when it came to distance shopping (catalog and Internet), the almost non-existence of the pre-buying advice was substituted by an open return policy from the retailer enabling the buyer to acquire this advice, most of the time when the garment arrived at home. Today with all the existing communication devices, people seem to take advantage of virtual reality to seek advice.

\section{The year is $\mathbf{2 0 1 0}$}

More than a decade ago we could read:

"The year is 2010. You want a new suit. You turn on the TV (Digital and Internet enabled) and 'dial' into you favourite tailor. Scanning his latest styles you find the type of garment in which you are interested, but it is not exactly right. You interact with it - narrowing the lapel, changing the pocket types, adding turn-ups, widening the legs. 
You view it in different colors and you 'try it on', superposing it onto your 3D exact scale and colour virtual image (download from your personal Internet file). It's a bit dark for your colouring, so you select a different color. You order it. Your exact order requirements - styling, fabric, individual measurements (from your Internet file) - are received on-line by your tailor, fabric automatically allocated, patterns automatically adapted to your size, marker produced and then cut, all without human intervention. Within a week you received your personalized, made-to-measure suit in the post....

Imagine going into a discreet private booth, standing for few seconds whilst light is shone onto you, coming out and being provided with a 3D full colour actual image of yourself complete with a full set of body measurements. The image is not a flat photograph; it is an electronic file whereby your exact body image can be viewed, in three dimensions, from any angle....

But so what? ...Why do we need it? ... Is it just a glorified electronic tape measure, or will its use lead to new era within the industry?" (Tait, )

At that time, according to Gray, there were only five companies in the world producing these types of scanners. Of those two - Hamamatsu (Japan) and Tecmath (Germany)-- used laser technology, which although perfectly safe, tends to raise unfounded fears with potential users. Telmat (France) uses photographic imagery front and back, which can create some inaccuracies. [TC]2 (America) the newest at the time and Wicks and Wilcox (UK) used white lights. In total, as mentioned by Gray to Tait during the interview, there were probably less than two dozen body scanners in use anywhere in the world, including those within research and education

The article stated that it was still impossible to say what the market share for made-to-order would be. Market research of that time showed that the general population would be willing to pay for a significant increase in value. What was understood of these terms still remains ambiguous but for Gray the high cost of producing and distributing the catalogues, their inflexibility once produced, and their associated 30 to $40 \%$ returns levels - over half being associated with wrong size ordering-indicates that, although very popular, there must be a better method for selling: the use of such technology, may be the way to do it.

\section{Results}

In our previous research we sought to validate the existce of the three variables: aesthetics, fit satisfaction/adjustment and socialization. We conducted different researches both in-store and with a catalog retailer.

\section{In Store}

In store we observed women in the fitting room area. With the exception of high end stores, who had invested and tried new technology, fitting rooms have only very slightly evolved over the last decades: a narrow area with the sole help of a mirror (when there is one in the fitting room) with, possibly, friends, relatives or a salesperson at the ready to give their appreciation of the garment tried.

In order to be able to capture consumers' natural behaviors we negotiated with the store managers to conduct observation surveys at the entrance of the fitting room area. Therefore the research was conducted based on the simple observation of women walking in and getting out of the fitting rooms.

\section{Aesthetics}

Since we needed to rely only on observations, as for as "how do women evaluate the aesthetics of a garment?" we equated aesthetics with the color choice. Our rationale was that a woman trying on the same exact garment with the same size in two different colors was necessarily trying to determine which one was best suited her image, i.e. her style and personality.

\section{Fit}

The fit was an easier concept to evaluate. Our rationale was that any woman walking in the fitting room with the exact two same garments, same color, in two different sizes obviously did not know which size corresponded to her body shape and size or again, did not know how to interpret the size label.

\section{Socialization}

Lastly to evaluate the socialization aspect, our rationale was that whoever was seeking advice/opinion from someone else (friend, relative or salesperson) was taking advantage of the situation to socialize by the same occasion. 
During our observations we found that: $17 \%$ of our sample size tried the same garment in different colors. One need to remember that these observations were done after the pre-selection made on the rack/shelve; $52 \%$ of the women brought the same garment in at least two different sizes to the fitting room which validate the low level of reliance of the size labeling system; $38 \%$ of the women coming to the fitting room were accompanied by relatives, spouse or friends which validate the social aspect.

\section{Distance shopping}

In order to do our observations for the distance shopping we were given access, by a large distance retailer, to merchandise orders and returns for a three months period. During that period, more than 700 garments were ordered whereas more than 325 were returned. A ratio exceeding any number found in the literature. It exceeds the usual $30 \%$ or the $40 \%$ generally mentioned for catalog sales. Since we had the details of each voucher we were able to identify the reason for each return. We found that $23 \%$ of the returns was based on what we call aesthetic and more than $60 \%$ of the returns was directly linked with sizes (too big, too small, ordered the wrong size, received the wrong size).

When were told that each return costs approximately ten dollars and that in order to be profitable returns should be around $30 \%$. It became obvious that one need to investigate the use of technologies such as 3D body scanner to improve this situation. We were convinced it could help retailers. Our next step was to investigate consumers' thoughts. Not only did we want to know their opinion about such technologies but we invited them to be scanned and then to give us their opinion about the implications of this technology on aesthetic, the fit and the social aspects.

\section{The year was almost 2010}

As we approached the year 2010, 3D body scanners growth was almost exponential. Many studies looked at the consumers' reaction to 3D body scanning especially for size and fit; yet few were combining 3D body scanning with styling and socialization. Burns and Bryant (2002), McKinnon and Istook (2002), Kontz and Gibson (2000) discussed the idea of virtually trying a garment which could eventually be leading to the creation of a virtual community (Kim and Jin, 2006), while Ashdown and Loker reminded us that the virtual environment was still under development. Moreover, most of these studies were done in western society.

A questionnaire was therefore developed to determine if the whole idea would be of interest for a young Asia market. A questionnaire was designed based on the literature. A total of 26 questions were divided into sections related to aesthetics, fit and socialization. Over a three months period, more than sixty young Asian women were scanned and asked to complete the questionnaire. Data analysis was done using statistical tools such as Excel and SPSS.

As stated in our literature, clothing serves different purposes; it fulfills a basic need but also serves to reflect one's personality. More than half of our sample agreed that clothing can help build their self-esteem. This validated Leroi-Gourhand that people not only use clothes to protect themselves and to cover their nudity but to ornate themselves (aesthetics).

Again, as stated in the literature, western women who are satisfied with their whole body or part of their body seem to be more satisfied with garment fit and vice et versa. Our results show that more than $50 \%$ of our participants expressed dissatisfaction on the majority of their body parts (14/19) and these same respondents were generally more dissatisfied with garment fit.

After being scanned we investigated if these young women would prefer to shop with a "smart card" (their avatar), almost as defined in what we could say was fiction only a decade ago, containing their body measurements and shape, virtually try on garments in a virtual world. Out of our sample, the majority, $93.5 \%$ try garments on before purchasing. The three main reasons stated are: they are concerned with garment fit (82\%); they want to buy the right size (63\%), and they wish to see how they look (44\%). This shows that these young women are concerned with the fit and the look. Over $90 \%$ of participants stated they would like to use a smart card as described before to enhance their shopping experience in situ or when searching the Web, although surprisingly, only $18 \%$ mentioned they would use it to show their friends and relatives.

We believe it is only a question of time (maybe during the year 2010) that people would take advantage of the communication devices for seeking for advice and socializing during their shopping in their virtual reality. 
One thing sure this year body scanners are definitely doing their entrance in the retail industry, they are in private retailers and in malls.

\section{Conclusion}

The advent of technologies such as 3D body scanning, avatar creation, and virtual try on the apparel industry had the tools to improve two of the main criteria in the purchase of a garment: aesthetics and fit. With the arrival of social network and rapid communication between individuals, such as Facebook or Twitter, it now has the tools to improve the third one: socialization.

One of the main drawbacks of distance selling can therefore be greatly reduced thereby improving both consumer satisfaction and retailer efficiency and profitability.

More research obviously needs to be conducted on the consumers' willingness to use such technologies (such as security issues) but at least it now looks like they may be able, in the near future, to fulfill all three criteria in the selection of a garment without having to endure hours and hours of shopping in crowded and often not very pleasant environments.

\section{References}

Anderson, G. (2004), If the Clothes Fit, Buy'Em, available at: www.retailwire.com/Print/PrintDocument.cfm?DOC ID =10058 (accessed December 2005).

Arthur, K. (2003). "Sizes give us fits", The Pantagraph, May 18, G1 pp. 1-4.

Armstrong, H. (1987), Patternmaking for fashion design. New York: Harper and Row.

Ashdown, S. P. (1998), "An investigation of the structure of the sizing systems: A comparison of three multidimensional optimized sizing systems generated from anthropometric data with the ASTM standard D5585-94", International Journal of Clothing Science and Technology, Vol. 10 No. 5, pp. 324-341.

Ashdown, S. P. (2003), "Sizing up the apparel industry". Cornell's Newsletter: Topstitch, Spring, pp.1.

Bickle, M. C., Kotsiopulos, A., Dallas, M. J., and Eckman, M. (1995), "Fit of women's jeans: an exploratory study using disconfirmation paradigm", Journal of Consumer Satisfaction /Dissatisfaction and Complaining Behavior, Vol. 8, pp. 208-213.

Boucher, F. (1996), Histoire du costume en occident, Flammarion, Paris, France.

Cain, G. (1950), The American way of designing, Fairchild Publications, New York, NY.

Consumer Reports (1996), "Why don't these pants fit?", May, pp. 38-9.

Curty, J.P., Declercq, M., Dechollain, C., and Joehl, N. (2007), Design and Optimization of Passive UHF RFID Systems. US: Springer.

Doss, F. D. (1990), "Clothing availability from department and specialty stores: Implications for self-esteem, body satisfaction, and design line preference of large-size women", Unpublished master's thesis, Virginia Tech, Blacksburg.

Efrat, S. (1982), The development of a method of generating patterns for clothing that conform to the shape of the human body. Working paper, Ph.D. thesis, School of Textile and Knitwear Technology, Leicester Polytechnic, pp. 234-235.

Erwin, M. D. and Kinchen, L. A. (1969), Clothing for moderns. $4^{\text {th }}$ edition, MacMillian, New York, NY.

Fallon, A. (1990), Culture in the mirror: Sociocultural determinants of body image. in T.F. Cash and T. Pruzinsky (Eds.), Body images: Development, deviance, and change The Guilford Press, New York: pp. 80-109.

Faust, M-E., Carrier, S. and Baptiste, P. (2006), "Variations in Canadian women's ready-to-wear standard sizes", Journal of Fashion Marketing and Management, Vol 10 No 1, pp. 71-83.

Faust, M-E. and Carrier, S . (2008), "A Global Size Label: A Step in Mass Customizing for the Apparel Industry", International Mass Customization Meeting (IMCM) + International Conference on Ergonomic, Technical and Operational Aspects of Product Configuration System (PETO), Conference dates: $19^{\text {th }}-20^{\text {th }}$ June, 2008, Copenhagen, Denmark.

Faust, M-E. and Carrier, S. (2010), "Women's wear sizing: a new labelling System" Journal of Fashion Marketing and Management, Vol. 14, No 1, pp. 88-126.

Gaut, B. and Lopes, D. M. (2001), The Routledge companion to aesthetics, London, UK, 
Goldsberry, E., Shim, S., and Reich, N. (1996), "Women 55 years and older: Part II. Overall satisfaction and dissatisfaction with the fit of ready-to-wear". Clothing and Textiles Research Journal, Vol 14 no 2, pp. 121-32.

Grogan, S. (1999), Body image: Understanding body dissatisfaction in men, women, and children. London: Routledge.

Harter, S. (1985), The self-perception profile for children: Revision of the Perceived Competence Scale for Children. Manual. Denver: University of Denver, U.S.A.

Haudek, C., Rorty, M., and Henker, B. (1999), "The role of ethnicity and parental bonding in the eating and weight concerns of Asian Americans and Caucasian college women", International Journal of Eating Disorders, Vol. 25, pp. 425-433.

Heatherton, T.F., Mahamedi, F., Striepe, M., Field, A., and Keel, P. (1997), "A Ten Year Longitudinal Study of Body Weight, Dieting, and Eating Disorder Symptoms", Journal of Abnormal Psychology, Vol. 106, pp. 117-125.

Higgins, E. T. (1987), "Self-discrepancy: A theory relating self and affect", Psychological Review, Vol. 94, pp. 319-340.

Higgins, E. T. (1989), "Self-discrepancy theory: What patterns of self-beliefs cause people to suffer" in Berkowitz L. (Eds.), Advances in experimental social psychology Vol. 22, pp. 93-136.

Horn, M. J. and Gurel, L. M. (1981), The second skin, $3^{\text {rd }}$ edition, Boston, Houghton Mifflin Company.

Huon, G. F. (1994), "Dieting, binge eating and some of their correlates among secondary school girls", International Journal of Eating Disorders, Vol. 15, pp. 159-164.

Hwang, J. (1996), "Relationships between body-cathexis, clothing benefits sought, and clothing behavior; and effects of importance of meeting the ideal body image and clothing attitude". Unpublished doctoral dissertation, Virginia Polytechnic Institute and State University, Blacksburg.

Jourard, S. M. (1958), Personal adjustment. New York: Macmillan, pp. 150-173.

Jourard, S. and Secord, P. (1955), "Body cathexis and the ideal female figure", Journal of Abnormal Social Psychology, Vol. 50, pp. 243-246.

Kalish, R. (1975), Late adulthood: Perspectives on human development. Monterey, Brooks/Cole Publishing Company, CA.

Kaiser, S.B. (1997), The social psychology of clothing: Symbolic appearances in context $2^{\text {nd }}$ edition, rev. Fairchild Publications, New York, NY.

Kefgen, M., and Touchie-Specht, P. (1986), Individually in clothing selection and personal appearance $4^{\text {th }}$ edition, Macmillian, New York, NY.

Kennedy, M. A., Templeton, L., Gandhi, A., and Gorzalka, B. B. (2004), "Asian body image satisfaction: Ethnic and gender differences across Chinese, Indo-Asian and European descent students", Eating Disorders: The Journal of Treatment and Prevention, Vol. 12 No 4, pp. 321-336.

Kinley, T. R. (2003), "Size variations in women's pants", Clothing and Textiles Research Journal, Vol. 21 No 1, pp. 19-31.

Kou, D., Zhao, K., Tao, Y., and Kou, W. (2006), Enabling Technologies for Wireless E-Business. Springer, Berlin Heidelberg.

Kurt Salmon Associates (2000), "Annual consumer outlook survey", Paper presented at a meeting of the American Apparel and Footwear Association Apparel Research Committee, Orlando, FL, November.

LaBat, K. L. and DeLong, M. R. (1990), "Body cathexis and satisfaction with fit of apparel", Clothing and Textiles Research Journal, Vol. 8 No 2, pp. 43-8.

Lai, K. Y. C. (2000), "Anorexia nervosa in Chinese adolescents: Does culture make a difference", Journal of Adolescence, Vol. 23, pp. 561-568.

Laurer, R. and Handel, W. (1977), The theory and application of symbolic interactionism. Houghton Mifflin, Boston, U.S.A.

Lee, A. M., and Lee, S. (1996), "Disordered eating and its psychosocial correlates among Chinese adolescents in Hong Kong", International Journal of Eating Disorders, Vol. 20, pp. 177-183.

Leung, F., Lam, S. and Sze, S. (2001), Cultural expectations of thinness in Chinese women. Eating Disorders, 9(4), pp. 339-350. 
Marina, A. (2005), "Communications clothing fit preferences of young female adult consumers", International Journal of Clothing Science and Technology, Vol. 17 No 1, pp. 52-64.

Marsella, A., Shizuru, L., Brennan, J. and Kameoka, V. (1981), "Depression and body image satisfaction", Journal of Cross-Cultural Psychology, Vol. 12, pp. 360-371.

Markee, N. L., Carey, I. L. S. and Pedersen, E. L. (1990), "Body cathexis and clothed body cathexis: Is there a difference?" Perceptual and Motor Skills, Vol. 70, pp. 1239-1244.

Mayes, K. (2008). Smart Cards, Tokens, Security and Applications, Springer, U.S.A.

Mintz, L. B. and Kashubeck, S. (1999), "Body image and disordered eating among Asian American and Caucasian college students: An examination of race and gender differences", Psychology of Women Quarterly, Vol. 23, pp. 781-796.

McVey, D. (1984), "Fit to be sold", Apparel Industry Magazine, February, pp. 24-26.

Monteath, S. A. and McCabe, M. P. (1997), "The influence of societal factors on female body image", Journal of Social Psychology, Vol. 137 No 6, pp. 708-728.

Mukai, T., Crago, M. and Shisslak, C. M. (1994), "Eating attitudes and weight preoccupation among female high school students in Japan", Journal of Child Psychology and Psychiatry, Vol. 35, pp. 677-688.

Mukai, T., Kambara, A. and Susaki, Y. (1998), "Body dissatisfaction, need for social approval and eating disturbances among Japanese and American college women", Sex Roles, Vol. 39, pp. 751-763.

Ogle, J. L. (1999), "Body satisfaction and weight-related appearance management in a two-way mirror: Mother-daughter interactions as mediation of the mass media's thin female ideal", Unpublished doctoral dissertation. lowa State University, U.S.A.

Otieno, R. (2000), The role of garment sizing in creation of consumer satisfaction: indications from focus group responses", Journal of Fashion Marketing and Management, Vol. 4 No 4, pp. 325-335.

Rasband, J. A. and Liechty, L. G. (2006), Fabulous Fit: Speed Fitting and Alteration, $2^{\text {nd }}$ edition, Fairchild Publications Inc, New York, NY, U.S.A.

Roach, M. and Eicher, J. (1973), The visible self: Perspectives on dress. Englewood Cliffs, Prentice-Hall, NJ, U.S.A.

Salem, D. (1990), "Black Women" in Organized Reform, 1890-1920, Carlson, New York, U.S.A..

Sanders, N. M. and Heiss, C. J. (1998), "Eating attitudes and body image of Asian and Caucasian college women", Eating Disorders, Vol. 6, pp. 15-27.

Schilder, P. (1935), The image and appearance of the human body. New York: International Universities Press in Landry Sault, N. (1994). Many Mirrors: Body image and Social Relation, NJ Rutgers Univ. Press, New Brunswick, U.S.A.

Schilder, P. (1950), The image and appearance of the human body. New York: International Universities Press. in Pylvänäinen P. (2003). Body Image: A Tripartite Model for Use in Dance/Movement Therapy, American Journal of Dance Therapy, Vol. 25 No 1, pp. 39-55.

Secord, P. F. and Jourard, S. M. (1953), "The appraisal of body-cathexis: Body-cathexis and the self", Journal of Consulting Psychology, Vol. 17 No 5, pp. 343-347.

Shen, L. and Huck, J. (1993), "Bodice pattern development using somatographic and physical data", International Journal of Clothing Science and Technology, Vol. 5 No 1, pp. 6-16.

Shim, S., Kotsiopulos, A. and Knoll, D. S. (1991), "Body cathexis, clothing attitude, and their relations to clothing and shopping behavior among male consumers", Clothing and Textiles Research Journal, Vol. 9 No 3, pp. 35-44.

Shim, S. and Bickle, M. C. (1994), "Benefit segments of the female apparel market: psychographics, shopping orientations, and demographics", Clothing and Textiles Research Journal, Vol. 12 No 2, pp. $1-12$.

Singh, D. (1993), "Adaptive significance of female physical attractiveness: Role of waist to hip ratio". Journal Pers Socio Psychology, Vol. 65 No 2, pp. 293-307.

Smathers, D. and Horridge, P. E. (1978-79), "The effects of physical changes on clothing preferences of the elderly women", International Journal of Aging and Human Development, Vol. 9 No 3, pp. 273-8.

Stone, G. (1962), Appearance and the self. in A.M. Rose (Ed.), Human behavior and social process, Hughton Mifflin, Boston: pp. 86-118. 
Sontag, M. S. and Schlater, J. D. (1982), "Proximity of clothing to self: Evolution of a concept". Clothing and Textiles Research Journal, Vol. 1 No 2, pp. 1-8.

South China Morning Post (2008), "Olympics organizers seek the perfect woman", February 16, pp.1. Tamburrino, N. (1992), "Apparel Sizing Issues, Part 1". Bobbin, Vol. 33 No 8, 44-59.

$[\mathrm{TC}]^{2}$. (2004), Size USA Let's size up America... The National Sizing Survey: Body Measurement and Data Analysis Reports on the U.S. Population. Prepared by [TC] $]^{2}$, Cary, North Carolina.

Thompson, J., Heinberg, L. J., Altabe, M. and Tantleff-Dunn, S. (1999), Exacting beauty: Theory, assessment, and treatment of body image disturbance. American Psychological Assocation, Washington, DC.

Tyrangiel, J. (2001), "Spree school”. Fortune, September 17, Vol. 144, pp. 250-252.

Wenger, J. (1969), "Clothing fit and body attitudes", Unpublished master's thesis, Colorado State University, Fort Collins.

Wendel, G. and Lester, D. (1988), "Body-cathexis and self esteem", Perceptual and Motor Skills, Vol. 67,538 .

Workman, J. E. and Lentz, E. S. (2001), "Measurement specifications for manufacturers' prototype bodies", Clothing and Textiles Research Journal, Vol. 18 No 4, pp. 251-259.

Xinhuanet (2002), "The Asian Ideal Body", Retrieved February 11, from, http://news.sina.com.cn/s/2002-04-11/0945542366.html

Yu, W. (2000), Subjective assessment of clothing fit”, in Fan, J. Yu, W. and Hunter, L. (2000), Clothing appearance and fit: Science and technology, Cambridge England: Woodhead Publishing, pp. 31-42.

Zakaria, N. (2010), The development of body sizing system for school-age children using the anthropometric data, Unpublished doctoral's thesis, Universiti Teknologi Mara, Kuala Lumpur, Malaysia. 